\title{
ORALIDADE, CORPO E MEMÓRIA ENTRE CONTADORES E CONIADORAS DE CAUSO GAÚCHOS
}

\section{Luciana Hartmann \\ Universidade Federal de Santa Catarina - Brasil}

Resumo: Num contexto onde a tradição oral se faz tão presente como na região da Campanha do Rio Grande do Sul, fronteira com Argentina e Uruguai, a observação das performances dos contadores de "causos" permite a consideração de que estas estão inseridas num complexo evento narrativo (Bauman, 1989), onde os diferentes contadores incorporam e reproduzem (incorporated knowledge - Hastrup, 1994), na sua ação mesma de contar, aspectos da memória do grupo. Esta memória revela-se não apenas nos termos do conteúdo das narrativas - no imaginário referido - mas através da própria vocalização e ação corporal intrínsecas à transmissão destas narrativas (Zumthor, 1993, 1997). Para analisar a performance destes contadores através da relação entre memória e corporalidade, elegi quatro caminhos. O primeiro busca identificar de que maneira o intercâmbio cultural característico desta que é uma região de fronteira se manifesta no corpo e na voz dos contadores. O segundo caminho diz respeito à formação do corpo dos contadores no seu trabalho cotidiano. $O$ terceiro viés de análise busca a relação entre a corporalidade e o meio (a paisagem) e o último depara a constituição da corporalidade dos contadores de causo a partir da uma experiência histórica marcante na região, a das guerras.

Palavras-chave: memória, performance, tradição oral.

Abstract: In a context where the oral tradition is so present as at Rio Grande do Sul Campaign, Argentina and Uruguai boarders, the observation of the performance of tellers of "causos" allows the consideration that they are inserted in a complex narrative event (Bauman, 1989), where the different tellers incorporate and reproduce (incorporated knowlewdge - Harstrup, 1994), in action itself of telling, the group memory aspects. This memory comes up not only in terms of the narrative contents in the referred imaginary - but through their own corporal intrinsic vocalization and action to the transmission of those narratives (Zumthor, 1993, 1997). To analyse the 
performance of those tellers through the relationship between memory and corporeality, I was selected four ways. The first one seeks to identify in which way the characterized cultural interchange of this that is a border region which is manifested in the body and voice of the tellers. The second way is regarded to tellers body formation in their everyday work. The third analyze seeks the relations between the corporeality and environment (landscape) and the last one shows the tellers corporeality constitution of the cases from the historical experience emphasized in the region and in the war.

Keywords: memory, oral tradition, performance.

"Bueno, vamos começar despacito...”. Assim começaria a prosa sem pressa de Seu Romão ou de Dona Marica, personagens e contadores da narrativa que agora vou "les" contar.

Numa faixa de terra que se estende por três países, ali, "no fim do fundo da América do Sul”, a noção de fronteira simbólica se faz sentir de maneira tocante, revelando-se não apenas na imutabilidade da paisagem mas na semelhança das vozes e gestos das mulheres e homens que vivem e narram esta região. Caminhando pelos campos ou perambulando pelas ruas de uma cidade, praticamente não se percebe "de que lado está”, mas o simples fato de fazer uma ligação telefônica internacional pode se tornar uma dificuldade real ou um rombo no orçamento. Bem, foi justamente aí, onde "tanto faz ser brasileiro como uruguaio, né” (e eu acrescentaria: ou argentino, né), que realizei minha pesquisa de campo durante os meses de inverno de 1997 e 1998. A pesquisa representa o aprofundamento de um trabalho sobre a performance dos contadores de causo gaúchos, iniciada ainda na graduação na área de Artes Cênicas, e busca neste momento as novas possibilidades que a abordagem antropológica pode propiciar. Neste sentido, a análise da performance passou a ser realizada considerando os contadores a partir de seu contexto cultural, e a constituição e manifestação da performance como uma "prática espetacular”" característica da região. A fronteira sudoeste do Rio Grande do Sul, que faz divisa com Argentina e Uruguai, foi escolhida para a pesquisa de campo devido à sua localização, na região da Campanha, que é formada por

\footnotetext{
1 Esta definição está relacionada às investigações da Etnocenologia, campo de pesquisa recentemente desenvolvido por Jean-Marie Pradier (1996), entre outros. A Etnocenologia propõe o estudo, nas diferentes culturas, das práticas e dos comportamentos humanos espetaculares organizados.
} 
extensas planícies e coxilhas, pequenas elevações de terra que não afetam a imensa horizontalidade do ambiente, e especialmente à sua história, ligada à ocupação das terras e colonização do estado, através de sangrentas disputas pelos limites territoriais e à produção extensiva de gado.

Inicialmente, em 1997, a pesquisa se centrou na zona rural desta região, onde se localizam as estâncias, grandes propriedades de terra nas quais vivem e trabalham os peões que lidam com o gado e onde estes peões se reúnem ao final do dia nos galpões, à beira do fogo, para tomar o chimarrão, momento em que as histórias, ou "causos” se tornam praticamente inevitáveis. Minhas primeira tentativa de entrar num galpão, no entanto, foi rapidamente frustrada por dois peões que permaneceram em frente à porta e solenemente me deram o seu "Boa nôte", sem se moverem do lugar. Eu não só não tinha licença como não tinha espaço físico para passar. Depois de dias assistindo novela com a cozinheira da estância, acabei encontrando uma possibilidade inusitada de entrada no galpão: o truco. Como eu fazia as refeições com os peões, numa noite comentei que jogava e, logo depois da janta, fui formalmente convidada a jogar e, conseqüentemente, a entrar no galpão. Dividimos as parcerias e, com o santo dos antropólogos a meu favor, foi justamente a minha que ganhou a partida, o que propiciou que nas noites seguintes eu voltasse sistematicamente a ser convidada pois, segundo eles, "não há nada pior do que perder para uma mulher”. Tudo isso resultou numa relação bem mais próxima com os peões e colocou-me em contato com seu palavreado menos formal e expressões, verbais e corporais, mais espontâneas. O truco, jogado na estância, transforma-se na manifestação simbólica de um duelo recheado de características campeiras. Todas as palavras e ações utilizadas durante o jogo refletem as atividades no campo. Desta maneira, o sete de espadas, uma das cartas de valor mais alto, é chamado de “manilha”, que é a corda que laça e derruba o touro, ou seja, a carta que pode vencer o jogo do adversário. Sentados em cadeiras de madeira baixas e com o espaldar inclinado, comuns em toda a região, eles espreitam as jogadas e passam suas senhas com o canto dos olhos, sem mover a cabeça, numa sutileza que começaria a revelar para mim uma nova nuance na rudeza característica daqueles homens. $\mathrm{O}$ truco, assim, não apenas representou a real possibilidade de minha inserção neste universo como me despertou para o fato de que nem só de causos vive um galpão.

Um fato que ocorreu já na primeira estância onde estive e que foi se tornando recorrente diz respeito à "negação à performance", pois todos os 
contadores com os quais tive contato, inclusive os reconhecidos como tal, hesitavam em assumir ou negavam num primeiro momento sua habilidade. E logo apressavam-se em se desculpar: "eu não conheço nada”, "eu não sei contar”, mas invariavelmente conheciam um grande contador, normalmente alguma pessoa mais idosa que morava nas proximidades. O curioso é que após dizerem isso, muitos começavam a me contar uma ótima história "como fulano contava”. Percebi então que, apesar de negarem, quase todos conheciam boas histórias mas talvez a diferença assumida por eles estivesse na maneira de contar, na habilidade daqueles que são contadores reconhecidos. Para Bauman (1977), a negação funciona como um padrão formal que, junto com outros como o uso de códigos especiais de linguagem, a presença de paralelismos, repetições e fórmulas especiais para iniciar as narrativas e o apelo à tradição, todos presentes, em maior ou menor grau, durante a narração de causos, garantem a compreensão e a participação da audiência e conferem ao contador que domina estes códigos maior respeitabilidade e poder frente aos seus ouvintes. Devido a este aspecto, inicialmente tive a sensação de que os contadores nunca estavam onde eu os procurava. E foi justamente em busca destes "narradores inexistentes" que parti, no ano seguinte, para uma nova fase da pesquisa, agora com todos os sentidos mais apurados e procurando seguir a trilha que ia sendo indicada pelos próprios sujeitos da pesquisa. Desta maneira, logo foi se estabelecendo uma "rede" de indicações de contadores, que fez com que também as áreas urbanas desta região fossem incluídas, já que muitos contadores, por diferentes motivos, atualmente residem na cidade. Neste momento foi-me necessário um exercício de descondicionamento e de abertura às novas possibilidades, já que, ao invés de uma roda de causos em frente do fogo, num galpão, passei a ouvir contadores em barbearias, pontos de táxi, bares e até na Câmara de Vereadores de uma cidade da região. ${ }^{2}$ Neste sentido, a cidade propunha uma atualização do olhar sobre estes novos espaços de sociabilidade que de alguma forma se relacionam, recriam ou representam o ambiente narrativo dos galpões. Esta rede de contadores era constantemente reiterada, com alguns nomes reconhecidos em toda a região, sendo que o fato de já ter conversado com um destes contadores amplamente reconhecidos servia como referência (e até como “legitimação” da pesquisa)

2 As cidades incluídas na pesquisa foram: Caçapava do Sul, Sant’Anna do Livramento, Quaraí, Uruguaiana e Alegrete.

Horizontes Antropológicos, Porto Alegre, ano 5, n. 12, p. 267-277, dez. 1999 
no momento do contato com outro contador. Nesta rede pude identificar o que classifiquei como diferentes categorias de contadores, sobre as quais não me aprofundarei aqui. Estas categorias incluem os "borrachos", cuja habilidade nas performances está relacionada ao seu estado de embriaguez (“com um pouco de trago é mais fácil soltar a língua”); os idosos, que são valorizados especialmente por terem realizado atividades hoje praticamente extintas, como tropeadas ou carreteadas; os tradicionalistas, ligados aos CTGs (Centros de Tradições Gaúchas), que preocupam-se com a memória da vida na Campanha e com a manutenção de uma determinada tradição -nesta categoria estão incluídos também a maior parte dos poetas; os historiadores auto-didatas, que são intelectuais da região, em geral moradores da zona urbana e pertencentes às famílias tradicionais, responsáveis pela história escrita das cidades em questão; e as mulheres, transmissoras das histórias da intimidade, da vida privada das famílias. De qualquer forma, as categorias não são excludentes e independentemente delas, na zona focalizada na pesquisa praticamente todas as pessoas conhecem algum causo e eventualmente contam-no, ainda que não se reconheçam ou não sejam reconhecidos como contadores.

Depois desta já não tão curta contextualização, passemos aos mecanismos de análise da performance. Para isso trabalharei com o conceito de "memória incorporada". Considero que todos estes diferentes contadores incorporam e reproduzem, na sua ação mesma de contar - sua performance aspectos da memória do grupo. Esta memória se revela não apenas nos termos do conteúdo das narrativas - no imaginário referido -, mas através da própria vocalização e ação corporal intrínsecas à transmissão oral destas narrativas (Zumthor, 1993, 1997). Sendo assim, interessa-me neste momento relacionar de que forma uma determinada memória é evidenciada e até mesmo recriada nas performances narrativas de contadores de causo gaúchos.

As questões que envolvem a corporalidade em termos de manifestação expressiva ou de construção estética tiveram, até os dias de hoje, comparativamente à outros objetos de estudo da antropologia, relativamente pouca atenção por parte dos pesquisadores. Apesar do impulso dado por Marcel Mauss, ainda na década de 20, com a noção de "técnica corporal”, e por Marcel Jousse, com a sua "antropologia do gesto", as pesquisas em antropologia do corpo permanecem muito relacionadas, senão à saúde e doença, às "representações” que este toma em diferentes contextos. Mauss (1974, p. 211), no entanto, caracterizou as técnicas corporais como "as maneiras como os homens, sociedade 
por sociedade e de maneira tradicional, sabem servir-se de seus corpos. Em todo caso, é preciso proceder do concreto ao abstrato, e não inversamente.” Sua proposta era de que no estudo destes "atos tradicionais eficazes", transmitidos de geração para geração, se poderia chegar à maneira concreta com que a estrutura social imprime sua marca nos indivíduos (Lévi-Strauss, 1974).

A corporalidade do gaúcho da região da Campanha do Rio Grande do Sul, apesar de cantada em versos e iconicamente divulgada para todo o país, também há muito pouco tempo começou a se tornar objeto de pesquisa. ${ }^{3}$ Muito relacionada à constituição da identidade, a manifestação corporal nesta região está ligada à condição de masculinidade. ${ }^{4} \mathrm{O}$ homem gaúcho celebra seu próprio corpo, sua força, sua virilidade e como membro desta "cultura narcísica" (Leal, 1992), ele incorpora a própria natureza que o cerca, revelada em metáforas como "levantou uma nuvem de quero-quero" ou "chucro como cavalo sem doma”. Mas mesmo questões como a predominância de uma identidade masculina nesse meio rapidamente começaram, durante minha pesquisa, a se mostrar mais fluidos, seja através das várias mulheres que também eram indicadas como contadoras, seja na presença feminina que compartilhava das rodas de causo.

A relação do corpo com a tradição ${ }^{5}$ e da tradição com a memória revela os contadores de "causo" como figuras-chave não só no processo de transmissão, mas de criação de uma corporalidade padrão nestas comunidades. A noção de que os corpos também são depositários da memória social e de que o conhecimento é incorporado (incorporated knowledge ${ }^{6}$ ), qualifica o corpo humano como o elo de ligação entre a natureza e a cultura, presente em todas as atividades humanas (Blacking, 1977). O corpo como mediador da relação do homem com o mundo também é abordado por Turner (1987) quando examina os processos criativos relacionados ao ritual como uma coadaptação de informações genéticas e culturais. Por sua própria forma, o corpo possui uma carga potencialmente expressiva e comunicativa. Neste sentido, as pesquisas

\footnotetext{
3 Ver Marocco (1996).

4 A tese de Leal (1989) é uma importante referência neste sentido. Ver ainda o artigo de Jardim (1995), que aborda a constituição da masculinidade a partir do corpo.

5 Considero "tradição" segundo definição de Foley (1995, p. xii): “[...] I have assumed tradition to be a dynamic, multivalent body of meaning that preserves much that um group has invented and transmitted but wich also includes as necessary, defining features both an inherent indeterminacy and a predisposition to various kinds of changes or modifications."

6 Pavis (1996) citando Harstrup.
} 
sobre teoria da comunicação desenvolvidas pela Escola de Palo Alto ${ }^{7}$ inferiram que dentre todos os comportamentos corporais possíveis, apenas alguns (aqueles que representam "encontros significativos”) são retidos pela cultura, constituindo códigos de comportamento corporal que conformarão o amplo sistema comunicacional. A comunicação corporal, considerada neste caso como intencional e codificada, realiza-se principalmente através de "gestos", que são ações corporais visíveis, pelas quais um certo significado é transmitido (Rector; Ramos, 1990).

Partindo destas considerações, elegi quatro caminhos para a abordagem da corporalidade dos contadores de causos gaúchos. O primeiro busca identificar de que maneira o intercâmbio cultural (ou interculturalidade) característico desta que é uma região de fronteira se manifesta no corpo e na vocalização dos contadores: sua movimentação está centralizada no tronco, da cintura para cima, sendo que eles em geral permanecem sentados ou de cócoras, enfatizando o gestual com mãos e braços e as expressões faciais. Ao contrário de regiões que sofreram influência mais direta das culturas negras, onde há grande movimentação também de quadris e pernas e as narrativas são contadas de pé (Mato, 1990), aqui possivelmente foram as culturas indígenas e as culturas européias, especialmente de Portugal e Espanha, que deixaram suas marcas ${ }^{8}$ mais profundas, manifestas também no uso de expressões híbridas entre as línguas dos dois países:

Lá onde eu moro, na casa de pedra, era um parente do Magalhães que morava lá, o João sabe [...]. Aí... porque (no tempo de guerra) sempre hay calúnia, não é? Hay... Um diz: “Olha, fulano é espião de fulano.” Então culparam, que ele era espião de outros. Olha, bateram no balicho dele e levaram tudo! E ele tinha mandado fazer essa casa, é Casa de Pedra o nome dela. É só pedra e barro. ${ }^{9}$

\footnotetext{
Chamada também de “collège invisible” por Winkin (1981), e composta, ao longo de sua história, por pesquisadores de diferentes áreas, como Birdwhistel, Hall, Goffman, Bateson, Scheflen e Sigman, foi responsável por importantes pesquisas sobre a teoria da comunicação, fundamentalmente superando a noção de comunicação que objetivava a transmissão de uma mensagem do emissor para o receptor e passando a considerá-la como um sistema de múltiplos canais onde o ator social participa integralmente, através de seus gestos, seu olhar, seu silêncio.

8 Ver Calamaro (1998), em seu artigo "De cuerpos y viajes - notas sobre la tranferencia intercultural de formas espetaculares”, onde apresenta hipóteses sobre os diferentes princípios estruturadores do corpo no Rio da Prata e na França para analisar as transformações sofridas na coreografia tango após a sua difusão.

9 Relato de Dona Marica, 93 anos, uruguaia de nascimento - Quaraí/RS.
} 
Ao invés de se colocarem numa postura verticalizada, posicionando-se, em relação aos seus ouvintes, de maneira “cenicamente” privilegiada, os contadores e contadoras com os quais tive contato não se levantam para contar seus causos e, se estão de pé, a indicação de que irão começar a narrativa é dada mesmo pelo agachar-se ou sentar-se em silêncio. A diferença em relação aos ouvintes, neste caso, é estabelecida não pelo posicionamento no espaço, mas pela utilização do tempo, através dos longos silêncios e pausas que vão marcando as narrativas desde o seu início.

O segundo caminho diz respeito à formação do corpo dos contadores no seu trabalho cotidiano: na lida campeira, tratando diretamente com os animais (principalmente gado e cavalos), os homens da região, pela necessidade de imposição e manifestação de força frente a estes, desenvolvem uma notável projeção do peito (Marocco, 1996), e fazem uso freqüente de onomatopéias e de fortes sons sem articulação que, de maneira visível (e audível), vão estar presentes nas narrativas contadas no final do dia:

Aí montaram acampamento, fizeram fogo de noite... De tardinha, quando escureceu um pouco, eles se atracaram naqueles cipó, de facão, e Páf! E Páf! Exatamente no lugar. Quando chegou no lugar o pai bateu e fez Pliiiim no facão, aquele barulho assim, e o pai disse: “Tá aqui Arnaldo[...].”10

A relação entre a corporalidade e o meio foi a terceira via encontrada para a interpretação da performance dos contadores gaúchos. A questão da horizontalidade dos gestos, revelada após a análise do material fotográfico extraído da pesquisa de campo, identifica uma forte influência da paisagem da região, extremamente plana, na expressão gestual utilizada pelos contadores. Também em termos de sua expressão vocal, o silêncio do pampa é substancializado nos intervalos e na cadência habitualmente lenta das narrativas:

Nós saía... tempo de inverno, não é, seis hora, seis e meia, nós já ia indo, aquela geada branqueaaando os campos... os cavalos pisavam na geada, resvalavam assim na geada... [...] Nós saía de lá do serviço as vezes quando tava entrando o sol assim, o sol bem baixiiiinho... ${ }^{11}$

${ }^{10}$ Relato de Seu Sadi, 50 anos, Uruguaiana/RS.

${ }^{11}$ Relato de Seu Rodolfo, 56 anos, Sant'Anna do Livramento/RS. 
Finalmente, o último viés de análise deparou a constituição da corporalidade dos contadores de causo a partir da uma experiência histórica marcante na região, a das guerras. A memoria dos conflitos armados, seja oriunda de uma vivência direta, seja motivada pelas próprias narrativas, gerou um tipo de manifestação corporal bastante característica, demonstrada através de uma forte economia de movimentos, da grande precisão gestual e de uma "postura guerreira”, que simula gestos de ataque e defesa durante a performance narrativa e transpõe o desafio para o nível da oralidade, como no caso da trova, do trote, da mentira, etc.:

Então o berço da Revolução de 26 foi aqui por isso. Isso eu posso te contar posteriormente, agora eu quero chegar no causo. E tinha um cidadão chamado João Cavalheiro. Esse João Cavalheiro andou fazendo umas mortes aí... e não que fosse bandido. Até... eu não vou te explicar bem agora prá poder chegar no causo depois. Ele... questão de defesa de honra, ele matou dois. Dois que teriam sido contratados para matá-lo e ele matou os dois caras. ${ }^{12}$

Todas estas questões permanecem em análise, visando um maior aprofundamento neste complexo "evento narrativo" (Bauman, 1989) que envolve, como procurei demonstrar acima, aspectos da memória de um grupo, que se manifestam em sua plenitude através do corpo, da voz e da narrativa dos contadores de causo. E na impossibilidade de apresentar integralmente a performance destes que são os personagens principais de minha narrativa, gostaria de concluir com o auxílio de Seu Romão, de 80 anos, natural de Uruguaiana/ RS e um de seus causos.

[...] tem o sobrenatural e tem a natureza divina. Porque tem muita gente que não crê na natureza divina. Eu tenho visto tanta coisa... nessa minha vida, com a idade que tô, que eu... eu fico pensando: o que é... o que é a natureza... tudo, tudo o que existe se mexendo na terra, o mole, o duro, o triste, como é que ele come? A lesma, prá sair daqui até lá a ponta daquela mesa ela leva um mês. E como é a caça prá comer? E... Eu vi também... Sempre digo, tem um homem que viu também. Me disse: “Eu vi, chê, eu vi.” Tem, até... no campo, longe, eu vi longe daqui. Uma lagartinha mais ou menos desse tamanho assim. No campo, de noite. Mas ela tem luz de tudo quanto é cor. E verde, azul, é encarnado, é branco... de toda a cor ela tem luz, tudo acesa na noite. No caminho... não

12 Relato do Seu Zeno, 68 anos, Caçapava do Sul/RS. 
me animei a matar. Deixa... Onde já se viu, o que é a natureza! A gente pode crer que a natureza é tão divina que a vagaluma tem luz própria dela mesmo. E acende tão claro como a luz daqui. Tem duas qualidades, tem a da serra... é grande assim, uma vagaluma grande. Mas os... Os focos são do lado da cabeça. De noite elas vem avoando prá você que é um auto, porque é as luz na frente. E a outra não, a outra... o fogo é prá trás. E como acende aquilo? E apaga? E ela não... Aonde que ela tem magneto? Aonde que ela tem chave? Aonde que ela tem isso, aonde que tem aquilo? Você pisa nela de noite ela espalha uma cor por tudo que é lado. A gente vê tanta coisa na natureza que... que contando parece mentira e é verdade.

\section{Referências}

BAUMAN, R. Verbal art as performance. Rowley, Mass: Newbury House Publishers, 1977.

BAUMAN, R. Story, performance and event: contextual studies of oral narrative. Cambridge: Cambridge University Press, 1989.

BLACKING, J. Towards na anthropology of the body. In: BLACKING, J. Anthropology of the body. London: Academic Press, 1977.

CALAMARO, L. De cuerpos y viajes - notas sobre la tranferencia intercultural de formas espectaculares. In: GREINER, C.; BIÃO, A. (Org.). Etnocenologia: textos selecionados. São Paulo: Annablume: GIPE-CIT, 1998.

FOLEY, J. M. The singer of the tales in performance. Indianapolis: Indiana University Press, 1995.

JARDIM, D. F. Performances, reprodução e produção de corpos masculinos. In: LEAL, O. F. (Org.). Corpo e significado: ensaios de antropologia social. Porto Alegre: Editora da Universidade/UFRGS, 1995.

LEAL, O. F. Honra, morte e masculinidade na cultura gaúcha. In: TEIXEIRA, S.; ORO, A. (Org.). Brasil \& França: ensaios de antropologia social. Porto Alegre: Editora da UFRGS, 1989. 
LEAL, O. F. Gauchos: male culture and identity in the Pampas. Thesis. Berkeley: University of California at Berkeley, 1992.

LÉVI-STRAUSS, C. Introdução à obra de Marcel Mauss. In: MAUSS, M. Antropologia e sociologia. Tradução de Mauro W. B. de Almeida. São Paulo: EPU, 1974. v. II.

MAROCCO, I. A. Le geste spetaculaire dans la culture "Gaucha" du Rio Grande do Sul - Brésil. Tese (Doutorado)-Université de Paris VIII, SaintDenis - Vincennes, 1996.

MATO, D. Cuenteros Afrovenezuelanos en acción. Oralidad: Lenguas, Identidad y Memoria de América, La Habana, n. 2, 1990.

MAUSS, M. As técnicas corporais. In: MAUSS, M. Antropologia e sociologia. Tradução de Mauro W. B. de Almeida. São Paulo: EPU, 1974. v. II.

PAVIS, P. Analyse du spetacle interculturel. In: INTERNATIONALE DE L’IMAGINAIRE: La Scéne et la Terre - Questions D’Ethnoscenologie. Paris: Maisons des Cultures du Monde, 1996.

PRADIER, J.-M. Ethnoscénologie: la profondeur des émergences. In: INTERNATIONALE DE L'IMAGINAIRE: Nouvelle série, Paris, Babel/ Maison des Cultures du Monde, 1996.

RECTOR, M.; RAMOS, A. Comunicação do corpo. São Paulo: Ática, 1990.

TURNER, V. Anthropology of performance. New York: PAJ Publications, 1987.

WINKIN, Y. (Org.). La Nouvelle Comunication. Paris: Éditions du Seuil, 1981.

ZUMTHOR, P. Introdução à poesia oral. Tradução de Jerusa Pires Ferreira, Maria L. D. Pochat e Maria I. de Almeida. Campinas: Hucitec, 1993.

ZUMTHOR, P. A letra e a voz: a "literatura” medieval. Tradução de Amálio Pinheiro e Jerusa Pires Ferreira. São Paulo: Companhia das Letras, 1997. 